\title{
Unionisation Structures, Productivity, and Firm Performance
}

\author{
Sebastian Braun*
}

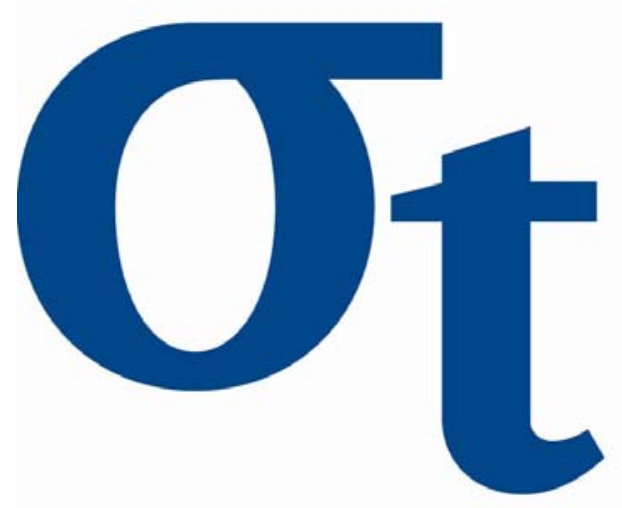

9)

$\forall$

6

* Humboldt-Universität zu Berlin, Germany

This research was supported by the Deutsche Forschungsgemeinschaft through the SFB 649 "Economic Risk". 


\title{
Unionisation Structures, Productivity, and Firm Performance*
}

\author{
Sebastian Braun ${ }^{\dagger}$ \\ Humboldt University Berlin.
}

May 5, 2009

\begin{abstract}
This paper studies how different unionisation structures affect firm productivity, firm performance, and consumer welfare in a monopolistic competition model with heterogeneous firms and free entry. While centralised bargaining induces tougher selection among heterogeneous producers and thus increases average productivity, firm-level bargaining allows less productive entrants to remain in the market. Centralised bargaining also results in higher average output and profit levels than either decentralised bargaining or a competitive labour market. From a welfare perspective, the choice between centralised and decentralised bargaining involves a potential trade-off between product variety and product prices. Extending the model to a two-country setup, I furthermore show that the positive effect of centralised bargaining on average productivity can be overturned when firms face international low-wage competition.
\end{abstract}

Keywords: Trade Unions, Productivity, Firm Performance, International Competition. JEL Classification: J50, D43, F16.

${ }^{*}$ The author is grateful to Michael C. Burda, Michael Kvasnicka, Thorsten Vogel, and participants of the Leibniz Seminar in Labour Economics and a seminar at Humboldt University Berlin for very helpful comments and suggestions. The project was supported by the Deutsche Forschungsgemeinschaft through the SFB 649 'Economic Risk'. All remaining errors are mine.

${ }^{\dagger}$ Sebastian Braun, Humboldt University Berlin, School of Business and Economics, Spandauer Straße 1, 10099 Berlin, Germany. Phone: +49 302093 5667. Email: sbraun@wiwi.hu-berlin.de. 


\section{Introduction}

Since the late 1970s, there has been a tendency among OECD countries to grant greater flexibility in the determination of wages. In fact, nine out of twenty-one member countries examined by the OECD $(2004)^{1}$ have allowed wages to adjust more freely to local conditions at the firm level, while not a single member country has moved to more centralised bargaining structures. In many European OECD countries, however, wages continue to be predominantly determined in industry-level collective agreements that specify an uniform wage rate common to all firms in an industry. This paper examines how different bargaining structures affect firm productivity, firm performance and consumer welfare in the long run.

What unions do to productivity and firm performance has been the topic of extensive research (cf. Metcalf, 2003, and Hirsch, 2004, for recent surveys). Conventional wisdom suggests that by raising pay unions hurt the financial performance of firms - 'unless there is a roughly equivalent union effect on productivity' (Metcalf, 2003: 118). Most of the theoretical literature on the relation between unionisation and productivity has focused on the incentives of unionised firms to innovate. Early studies by Grout (1984) and van der Ploeg (1987) have pointed to a hold-up problem associated with unionisation. Once a firm has incurred the sunk costs of investment, unions can capture part of the innovation rent by demanding higher wages. The incentives of firms to innovate are therefore decreasing in union bargaining power. If firms, however, invest strategically so as to increase their market shares and profits, unionised enterprises may enjoy a strategic advantage over their non-unionised competitors (cf. Tauman and Weiss, 1987; Ulph and Ulph, 1994; Ulph and Ulph, 2001). Existing studies have focused on markets that are characterised by a small and fixed number of firms. The market structure in these studies is exogenously given. Unionisation, however, is likely to influence the number and, equally important, the characteristics of firms that survive in the long-run; and financial performance depends crucially on the market environment.

My objective in this paper is to analyse the interactions between bargaining structures, the

\footnotetext{
${ }^{1}$ The OCED does not assess wage setting institutions in central and eastern European OECD countries before the 1990s. Data on the bargaining level are also not provided for Iceland, Luxembourg, Mexico, Turkey and South Korea.
} 
market environment and firm performance. To that end, I study a monopolistic competition model in the spirit of Melitz and Ottaviano (2008) with heterogeneous firms and free entry. The model incorporates both differences in firm productivity and endogenous mark-ups that respond to the intensity of competition in a market. The intensity of competition is summarised by the number of competing enterprises and their average price level. I distinguish between three different labour market regimes. Wages are either determined in a perfectly competitive labour market, set by firm-specific unions, or fixed by a binding, sector-wide wage agreement. With decentralised bargaining, wages are firm-specific and increase in productivity. With sector-level bargaining, in contrast, wages are uniform, a singular wage rate that is binding for each and every firm.

The model highlights two effects of unionisation that have been largely overlooked in previous work. First, sector-level bargaining (but not firm-level bargaining) induces tougher selection among heterogeneous producers and changes the productivity distribution among surviving firms. In particular, by increasing wages for all firms, centralised bargaining acts a barrier to entry for low-productivity firms. Second, both bargaining regimes discourage entry and decrease competitive pressures by raising pay. Less intensive competition ceteris paribus results in higher profits of surviving firms and allows less productive enterprise to remain in the market.

Compared to the competitive benchmark, centralised bargaining increases average productivity (due to the selection effect) and boosts average output and profits (due to a combination of the selection and the anti-competitive effect). Firm-level bargaining, in contrast, by allowing less productive firms to survive, decreases average firm productivity and performance. At the level of the individual firm, unionisation creates winners and losers. Decentralised agreements benefit low productivity firms and harm high productivity firms, while the opposite is true for centralised wage agreements. Regarding consumer welfare, the choice between the two bargaining regimes can involve a trade-off between product prices and product variety. Firm-level bargaining tends to increase product variety but also induces a less favourable price distribution than centralised bargaining does.

My result that wage compression can be beneficial for productivity is related to earlier work 
by Moene and Wallerstein (1997). Formalising arguments made in the Swedish debate over 'solidaristic' bargaining (Rehn, 1952), Moene and Wallerstein (1997) compare the effects of decentralised and centralised wage bargaining in a vintage capital model of a small open economy in which the price of output is exogenously given. Firms decide when to open new, more productive plants and when to shut down older, less productive ones. Under decentralised bargaining, less productive plants pay lower wages and can therefore remain in the market for a longer time. Centralised bargaining, in contrast, levels interplant wage differentials and drives less productive plants out of the market. Apart from the very different modeling strategy, the principal difference between Moene and Wallerstein (1997) and the present paper is my focus on the intensity of competition as an additional channel through which unionisation can influence productivity and firm performance. ${ }^{2}$ The effects of different unionisation structures on firm productivity are also examined by Haucap and Wey (2004) who find that centralised bargaining provides the greatest incentives to innovate. They develop their argument in an unionised oligopoly model with a fixed number of firms and focus on the interaction between bargaining structures and the hold-up problem associated with unionisation. In contrast to their paper, I take a long-run perspective and examine how different unionisation structures affect firm performance in a model with an endogenous market structure.

Extending the model to a two-country setup, I furthermore show that the positive effect centralised bargaining has on average productivity may vanish when firms face international lowwage competition. While both the selection and the anti-competitive effects are still at work in an open economy, collective bargaining, by increasing wages, also induces firms to relocate to the non-unionised country. In such a setting, trade liberalisation can reduce competition, harm productivity, and depress welfare in the high wage country.

The paper is structured as follows: Section 2 presents the basic model setting which I then use in Section 3 to analyse the effects of unionisation structures on firm productivity and firm performance. Section 4 considers consumer welfare and studies the impact of wage bargaining on product variety and product prices. Section 5 discusses the implications of collective bargaining

\footnotetext{
${ }^{2}$ The present paper also shows that the choice between centralised and decentralised bargaining involves a trade-off between product prices and product variety. In Moene and Wallerstein (1997), in contrast, output prices are exogenously given.
} 
in an open economy. Section 6 summarises the main findings and concludes.

\section{The Model Setting}

I consider a two-sector economy with a representative consumer that inelastically supplies $L$ units of labour. ${ }^{3}$

\subsection{Preferences and Demand}

Preferences of the representative consumer are given by a quasilinear utility function defined over a continuum of differentiated varieties and a homogeneous numeraire good:

$$
U=q_{0}^{c}+\alpha \int q_{i}^{c} d i-\frac{1}{2} \gamma \int\left(q_{i}^{c}\right)^{2} d i-\frac{1}{2} \eta\left(\int q_{i}^{c} d i\right)^{2}
$$

where $q_{0}^{c}$ and $q_{i}^{c}$ are the consumption levels of the numeraire good and of variety $i \in \Omega$, respectively. The parameters $\alpha>0, \eta>0$ determine demand for the differentiated varieties relative to the numeraire good, while $\gamma>0$ is an (inverse) measure of the degree of product differentiation between varieties. In the limit, as $\gamma$ approaches 0 , varieties become perfect substitutes and the consumer is only concerned about the total consumption level over all varieties, $Q^{c}=\int_{i \in \Omega} q_{i}^{c} d i$. Increases in $\alpha$ and decreases in $\eta$ both boost demand for the differentiated varieties relative to the numeraire.

The representative consumer maximises (1) subject to her budget constraint. Let $\Omega^{*} \subset \Omega$ be the subset of varieties that are actually consumed $\left(q_{i}^{c}>0\right)$. The constraint can then be written as

$$
I=q_{0}^{c}+\int_{i \in \Omega^{*}} p_{i} q_{i}^{c} d i
$$

where $I$ represents income, $p_{i}$ is the price of variety $i$, and the price of the numeraire good has been normalised to unity. Provided that the representative consumer has positive demand for the numeraire, utility maximisation yields the following inverse demand function for each

\footnotetext{
${ }^{3}$ The model framework is similar to Melitz and Ottaviano (2008) but in addition to their work I study the effects of firm- and sector-level bargaining.
} 
consumed variety $i$ :

$$
p_{i}=\alpha-\gamma q_{i}^{c}-\eta Q^{c}
$$

Let $N$ measure the number of consumed varieties in $\Omega^{*}$. By inverting (3), demand for these varieties can be expressed as follows:

$$
q_{i}=\frac{\alpha}{\eta N+\gamma}-\frac{1}{\gamma} p_{i}+\frac{\eta N}{\eta N+\gamma} \frac{1}{\gamma} \bar{p}, \forall i \in \Omega^{*}
$$

where $\bar{p}=(1 / N) \int_{i \in \Omega^{*}} p_{i} d i$ is the average price of all consumed varieties.

With quasi-linear preferences all income effects are swept up by the numeraire good and $q_{i}$ is independent of $I$. Therefore, admittedly, the model has a strong partial equilibrium flavour. However, the price elasticity of demand derived from a quasi-linear utility function has the considerable merit that it is not fixed as in the case of Constant Elasticity of Substitution (CES) preferences but related to the intensity of competition. In fact, the price elasticity $\epsilon_{i} \equiv\left|\frac{\partial q_{i}}{\partial p_{i}} \frac{p_{i}}{q_{i}}\right|=\left[\left(p_{\max } / p_{i}\right)-1\right]^{-1}$ is inversely related to the upper price bound $p_{\max }$, at which demand for a variety $i$ is driven down to zero (i.e. $q_{i}\left(p_{\max }\right)=0$ ). The price bound is a summary statistic for the 'toughness' of competition and given by

$$
p_{\max } \equiv \frac{1}{\eta N+\gamma}(\gamma \alpha+\eta N \bar{p})
$$

which from (3) has to be smaller than $\alpha$. The price bound is decreasing in the number of competing enterprises and increasing in the average price level. In line with the empirical evidence (see, for instance, Campbell and Hopenhayn, 2005, and Tybout, 2003), an increase in the intensity of competition, as indicated by a lower price bound, thus increases the price elasticity of demand $\epsilon_{i}$ at any given $p_{i}$.

The indirect utility function associated with (1) can be used to assess welfare in the model. Using the demand system (4) utility can be written as

$$
U=I^{C}+\frac{1}{2}\left(\eta+\frac{\gamma}{N}\right)^{-1}(\alpha-\bar{p})^{2}+\frac{1}{2} \frac{N}{\gamma} \theta_{p}^{2}
$$


where $\theta_{p}^{2}=(1 / N) \int_{i \in \Omega^{*}}\left(p_{i}-\bar{p}\right)^{2} d i$ is the variance of prices. Welfare is thus decreasing in the average price level $\bar{p}$ but rises with increases in the variance of prices $\theta_{p}^{2}$. The utility function also exhibits love of variety: holding the distribution of prices constant, welfare is increasing in product variety $N$.

\subsection{Production, Firm Behaviour and Entry}

The numeraire good is sold in a perfectly competitive market and produced under constant returns to scale. One unit of labour is required to produce one unit of the numeraire. As the price of the numeraire is normalised to one, this implies a wage rate of unity in the numeraire good sector.

In the differentiated product sector entry is costly. I take a long-run perspective and assume that there exists a large (unbounded) pool of prospective entrants. ${ }^{4}$ In order to enter the market, firms have to incur fixed start-up costs of $f_{E}$. Unit costs of production are given by $c w(c)$ with $c$ denoting unit labour requirement and $w(c)$ being the (potentially firm-specific) wage rate. Prior to entry the cost level $c$ of a firm is unknown and each start-up learns its cost level only after it has made the initial investment. The cost level is drawn from a common and known distribution $G(c)$ with support on $\left[0, c_{M}\right]$. Following Melitz and Ottaviano (2008), I assume that the productivity draw $1 / c$ follows a Pareto distribution with shape parameter $k \geq 1 .^{5}$ Accordingly, the distribution of cost draws $G(c)$ is given by

$$
G(c)=\left(\frac{c}{c_{M}}\right)^{k}, c \in\left[0, c_{M}\right]
$$

The shape parameter $k$ determines the dispersion of cost draws. For $k=1$ the latter is uniformly distributed on the support. As $k$ increases, the relative frequency of start-ups with high cost levels increases as well.

After a firm has drawn its productivity parameter $c$ it decides whether to remain in the market

\footnotetext{
${ }^{4}$ A short-run version of the model could be constructed by considering a fixed number of incumbents only (cf. Melitz and Ottaviano, 2008).

${ }^{5}$ Using firm-level data for manufacturing industries in 11 EU countries, Del Gatto et al. (2006) provide evidence that the Pareto is a good approximation to the distribution of firm productivity across sectors and countries. They suggest that on average the shape parameter $k$ is close to two.
} 
and to start production. A firm will do so whenever it can cover its marginal costs and earn nonnegative (gross) profits. All other entrants leave the market. Surviving firms then maximise their profits $\Pi(c)=[p(c)-c w(c)] q(c)$ taking the number of firms in the market and the average price level as given. Using the demand function in (4), the first-order condition of a firm with cost draw $c$ reads

$$
q(c)=\frac{1}{\gamma}[p(c)-c w(c)]
$$

By solving equation (4) for the price level, substituting into (8) and also using the definition of $p_{\max }$ the profit-maximising price $p(c)$ can be written as

$$
p(c)=\frac{1}{2}\left[p_{\max }+c w(c)\right] .
$$

Hence, the price level does not only increase with unit costs $c w(c)$ but is also (inversely) related to the endogenous degree of competitiveness in the market. The profit-maximising output level $q(c)$, the corresponding profit level $\Pi(c)$ and the markup $\mu(c)=p(c)-c w(c)$ of a firm can also be expressed in terms of $c w(c)$ and $p_{\max }$ only:

$$
\begin{aligned}
q(c) & =\frac{1}{2 \gamma}\left[p_{\max }-c w(c)\right], \\
\Pi(c) & =\frac{1}{4 \gamma}\left[p_{\max }-c w(c)\right]^{2}, \\
\mu(c) & =\frac{1}{2}\left[p_{\max }-c w(c)\right] .
\end{aligned}
$$

Now let $c_{\max }$ reference the cost level of a firm that just earns zero gross profits. This firm's profit-maximising price level is driven down to its marginal cost and the firm is therefore just indifferent about remaining in the market. All firms with $c<c_{\max }$ are sufficiently productive to earn positive gross profits and therefore stay in the market and start production. In contrast, firms with cost levels above $c_{\max }$ exit. ${ }^{6}$ From (11) one can directly infer that

$$
c_{\max }=\frac{p_{\max }}{w\left(c_{\max }\right)} .
$$

\footnotetext{
${ }^{6}$ I will assume in the following that $c_{\max }$ is below $c_{M}$ and hence firms with a cost draw of between $c_{\max }$ and $c_{M}$ have to leave the market.
} 
The cut-off level is therefore negatively related to the wage rate of the marginal firm but positively to the (endogenous) upper price bound $p_{\max }$. Strong competitive pressures thus deter entry of low productivity firms.

Prior to entry, i.e. before a prospective entrant has undertaken its initial investment, expected gross profits are given by $\int_{0}^{c_{\max }} \Pi(c) d G(c)$. Unrestricted entry ensures that expected gross profits are driven down to the fixed start-up cost $f_{E}$ and hence total expected profits are driven down to zero. Accordingly, the free-entry equilibrium condition is given by

$$
\int_{0}^{c_{\max }} \Pi(c) d G(c)=f_{E}
$$

\subsection{Labor Market Regimes}

Wages in the differentiated good sector can either be determined in a perfectly competitive labour market, fixed by an industry-wide wage agreement, or set by a firm-specific union. These three different scenarios $\rho=P, U, D$ have the following properties:

1. Competitive Labour Market $(\rho=P) .{ }^{7}$ Wages in the differentiated good sector just equal the outside option of workers. The latter is determined by the wage rate in the competitive numeraire sector and equals unity. Therefore, in a flexible labour market the corresponding wage rate $w^{P}$ is given by $\bar{w}=1$.

2. Centralised Bargaining $(\rho=U)$. An industry union sets an uniform industry-wide wage floor above the competitive wage rate. The wage is given by $w^{U}=\theta \bar{w}=\theta$ with $\theta>1$.

3. Decentralised Bargaining $(\rho=D)$. Union activities are specific to a firm. In particular, there exist $N$ firm-level unions and each union sets a wage rate for its respective firm. In doing so, unions maximise total firm-level rents $[w(c)-\bar{w}] E(c)$, where firm-level employment $E(c)$ is given by $c q(c)$. Solving the maximisation problem then yields a firm-specific wage rate of $w^{D}(c)=\left(p_{\max }+c\right) / 2 c .^{8}$

\footnotetext{
${ }^{7}$ This case has been analysed by Melitz and Ottaviano (2008).

${ }^{8}$ Here I also assume that the bargaining takes place after the entry decision has been made and that firms retain their right-to-manage.
} 
Centralised and decentralised wage bargaining differ in one key characteristic that is crucial for the results to follow. While firm-level bargaining accounts for idiosyncratic firm characteristics, an industry wide bargaining agreement specifies an uniform wage that is binding for each and every firm. More specifically, under firm-level bargaining the wage rate is increasing in firm productivity (or decreasing in the cost level $c$ ). In contrast, the wage rate under centralised wage bargaining is independent from productivity and has to be paid by any firm in the differentiated product sector. In fact, centralised bargaining agreements are frequently criticised for suppressing regional or plant-specific wage differentials. Although the uniform wage rate $w^{U}$ could in principle be derived endogenously, e.g. from a simple monopoly union model, a binding and exogenously given wage $\theta>1$ is the simplest and most flexible way to model this characteristic in the present context. ${ }^{9}$ Of course, as modelled here, the uniform wage rate $w^{U}>\bar{w}$ could also result from a (binding) minimum wage imposed by the state.

\section{Unionization Structures, Productivity, and Firm Performance}

In this section I use the model described above to analyse the effect of the different labour market regimes on average firm productivity and firm performance. To build intuition, I start with treating the market structure in the differentiated good sector, as summarised by $p_{\max }$, as exogenously given. By substituting the corresponding wage rate into equation (13) the cost cut-off level $c_{\max }^{\rho}$ under each labour market regime $\rho=P, U, D$ can be written as

$$
c_{\max }^{P}=p_{\max }^{P}, \quad c_{\max }^{U}=\frac{p_{\max }^{U}}{\theta}, \quad c_{\max }^{D}=p_{\max }^{D}
$$

Inspecting equations (15) shows that for any exogenously given $p_{\max }^{\rho}=p_{\max }(\forall \rho=P, U, D)$ the cost cut-off level is lowest under centralised wage bargaining. Centralised bargaining induces

\footnotetext{
${ }^{9}$ In order to derive a closed form solution for $w^{U}$ from a monopoly union model, one has to assume that the industry-level union does not take into account its influence on $p_{\max }$. Introducing the free parameter $\theta$ will furthermore prove helpful in the following as some of the results depend on the exact magnitude of the binding wage floor. A possible parameter value of $\theta$ is the average wage rate received by workers under decentralised bargaining.
} 
tougher selection by increasing marginal production costs of all firms. Entry of low productivity enterprises is thus deterred. I call this the selection effect of centralised bargaining. With firmlevel bargaining, in contrast, wages are firm-specific. Less productive firms have to pay lower wages and the marginal firm just pays the competitive unit wage $w^{D}\left(c_{\max }\right)=1^{10}$. Consequently, the selection effect is absent under firm-level bargaining; for any given $p_{\max }$ the cost cut-offs $c_{\max }^{P}$ and $c_{\max }^{U}$ are identical. Notice that this result is not specific to the monopoly union model but follows from any model of union behaviour that yields $w\left(c_{\max }\right)=\bar{w}$.

Consider next the profit level of a firm producing with cost $c$ under labour market regime $\rho=P, U, D:$

$$
\Pi^{P}(c)=\frac{1}{4 \gamma}\left(p_{\max }^{P}-c\right)^{2}, \quad \Pi^{U}(c)=\frac{1}{4 \gamma}\left(p_{\max }^{U}-c \theta\right)^{2}, \quad \Pi^{D}(c)=\frac{1}{16 \gamma}\left(p_{\max }^{D}-c\right)^{2}
$$

Given an exogenous level of competition, profits of a firm with cost draw $c$ are highest in the competitive environment. By increasing wages above the competitive level, both centralised and decentralised wage bargaining ceteris paribus depress profits. ${ }^{11}$ Whether a firm is better off under firm- or under sector-level bargaining depends on its cost draw $c$. Firms with a cost level of above $p_{\max } /(2 \theta-1)$ prefer the decentralised over the centralised bargaining mode. Highproductivity firms, in contrast, are better off under an uniform wage agreement.

So far I have taken $p_{\max }$ as exogenously given. In equilibrium, the cost cut-off level $c_{\max }$ and the corresponding upper price bound $p_{\max }$ are determined by the free entry condition (14). Using equations (15) and (16), the free entry condition for labour market regime $\rho=P, U, D$ can be rewritten as

$$
\begin{aligned}
& \int_{0}^{c_{\max }^{P}} \frac{1}{4 \gamma}\left(c_{\max }^{P}-c\right)^{2} d G(c)=f_{E}, \quad \int_{0}^{c_{\max }^{U}} \frac{\theta^{2}}{4 \gamma}\left(c_{\max }^{U}-c\right)^{2} d G(c)=f_{E}, \\
& \int_{0}^{c_{\max }^{D}} \frac{1}{16 \gamma}\left(c_{\max }^{D}-c\right)^{2} d G(c)=f_{E} .
\end{aligned}
$$

\footnotetext{
${ }^{10}$ Evaluating $w^{D}(c)$ at $c=c_{\max }$ yields $p_{\max } / 2 c_{\max }+1 / 2$. From $c_{\max }=p_{\max } / w\left(c_{\max }\right)$, it then follows that $w^{D}\left(c_{\max }\right)=1$.

${ }^{11}$ The marginal firm under decentralised wage bargaining is an exception in this regard because it just has to pay the competitive wage rate.
} 
The equilibrium cost cut-off levels and upper price bounds are then given by: ${ }^{12}$

$$
\begin{aligned}
c_{\max }^{P} & =p_{\max }^{P}=\left[2(k+1)(k+2) \gamma\left(c_{M}\right)^{k} f_{E}\right]^{1 /(k+2)}, \\
c_{\max }^{U} & =\frac{p_{\max }^{U}}{\theta}=\left[\frac{1}{\theta^{2}}\right]^{1 /(k+2)}\left[2(k+1)(k+2) \gamma\left(c_{M}\right)^{k} f_{E}\right]^{1 /(k+2)}, \\
c_{\max }^{D} & =p_{\max }^{D}=4^{1 /(k+2)}\left[2(k+1)(k+2) \gamma\left(c_{M}\right)^{k} f_{E}\right]^{1 /(k+2)} .
\end{aligned}
$$

Comparing these cut-off levels and price bounds yields

Proposition 1. The orderings of the cost cut-off levels, $c_{\text {max }}^{\rho}$, and the upper price bounds, $p_{\text {max }}^{\rho}$, under the different labour market regimes $\rho=P, U, D$ are as follows:

$$
\begin{aligned}
& \text { i. } c_{\text {max }}^{D}>c_{\text {max }}^{P}>c_{\text {max }}^{U}, \\
& \text { ii. } p_{\max }^{P}<\min \left[p_{\max }^{U}, p_{\max }^{D}\right], \\
& \text { iii. } p_{\max }^{U}>(<) p_{\max }^{D} \text { for } \theta^{k}>(<) 4 .
\end{aligned}
$$

The equilibrium cost cut-off is thus lowest under centralised bargaining and highest under firm-level bargaining. The overall intensity of competition is highest (the upper price bound is lowest) in the competitive environment. These two findings are directly related to our previous observations that for any given market structure centralised bargaining induces tougher selection and both bargaining regimes reduce profits.

The selection effect of centralised bargaining drives the least efficient firms out of the market and therefore decreases the cost cut-off. At the same time, by decreasing expected profits of potential entrants, ${ }^{13}$ centralised bargaining also discourages firm entry and thus reduces the 'toughness' of competition. Since tougher competition also induces tougher selection, the anti-competitive effect works against but does not overturn the selection effect. Firm-level bargaining, in contrast, does not induce tougher selection but ceteris paribus only decreases expected profits of surviving firms. Lower expected profits again discourages entry and reduces the intensity of competition.

\footnotetext{
${ }^{12}$ These cut-off levels are derived under the assumption that $c_{\max }^{\rho}<c_{M}$. For the different labour market regimes $\rho=P, U, D$ this assumption is fulfilled for $c_{M}>\sqrt{2(k+1)(k+2) \gamma f_{E}}, c_{M}>(1 / \theta) \sqrt{2(k+1)(k+2) \gamma f_{E}}$, $c_{M}>2 \sqrt{2(k+1)(k+2) \gamma f_{E}}$, respectively.

${ }^{13}$ Centralised bargaining does not only decrease expected profits by increasing pay but also by reducing the ex ante probability of survival for potential entrants.
} 
Firms can then charge higher equilibrium prices and entrants with a relatively high cost level that would not break-even in a perfectly competitive environment (let alone under centralised bargaining) remain in the market. Finally, comparing the 'toughness' of competition under centralised and decentralised wage bargaining shows that the upper price bound is higher under the former if and only if $\theta^{k}>4$. Competition is therefore weaker under regime $U$ when the specified wage floor $\theta$ is relatively high and/or the distribution of cost draws is skewed towards less productive firms.

Having endogenised the market structure (as summarised by $p_{\max }$ ), I will now assess how the different labour market regimes affect firm-level performance. The (unweighted) average of some performance measure $z^{\rho}(c)$ under regime $\rho=P, U, D$ is given by $\bar{z}^{\rho}=\left[\int_{0}^{c_{\max }^{\rho}} z^{\rho} d G(c)\right] / G\left(c_{\max }^{\rho}\right)$. The firm-level cost average $\bar{c}^{\rho}$, average output $\bar{q}^{\rho}$, and the average profit level $\bar{\Pi}^{\rho}$ can all be written as simple functions of $c_{\max }^{\rho}$ and $p_{\max }^{\rho}$ only:

$$
\begin{aligned}
& \bar{c}^{P}=\frac{k}{k+1} c_{\text {max }}^{P}, \bar{c}^{U}=\frac{k}{k+1} c_{\text {max }}^{U}, \bar{c}^{D}=\frac{k}{k+1} c_{\text {max }}^{D}, \\
& \bar{q}^{P}=\frac{1}{2 \gamma(k+1)} p_{\max }^{P}, \bar{q}^{U}=\frac{1}{2 \gamma(k+1)} p_{\text {max }}^{U}, \bar{q}^{D}=\frac{1}{4 \gamma(k+1)} p_{\text {max }}^{D}, \\
& \bar{\Pi}^{P}=\frac{\left(p_{\max }^{P}\right)^{2}}{2 \gamma(k+1)(k+2)}, \bar{\Pi}^{U}=\frac{\left(p_{\max }^{U}\right)^{2}}{2 \gamma(k+1)(k+2)}, \bar{\Pi}^{D}=\frac{\left(p_{\max }^{D}\right)^{2}}{8 \gamma(k+1)(k+2)} .
\end{aligned}
$$

Combining these performance measures with equations (18) to (20) yields

Proposition 2. The orderings of the firm-level cost averages, $\bar{c}^{\rho}$, the average output levels, $\bar{q}^{\rho}$, and the average profit levels, $\bar{\Pi}^{\rho}$, under the different labour market regimes $\rho=P, U, D$ are as follows:
i. $\bar{c}^{D}>\bar{c}^{P}>\bar{c}^{U}$
ii. $\bar{q}^{U}>\bar{q}^{P}>\bar{q}^{D}$
iii. $\bar{\Pi}^{U}>\bar{\Pi}^{P}>\bar{\Pi}^{D}$.

Compared to both the competitive environment and to firm-level bargaining an uniform wage above the competitive level boosts average firm productivity (lowers the cost average), and leads to an increase in average output and profits. The positive impact on average productivity follows 
directly from the lower cost cut-off level (cf. Proposition 1i.). Two distinct effects are responsible for the positive effect on average output and profits. First, the productivity-enhancing effect of centralised wage bargaining also increases average output and profits because high productivity firms generally produce and earn more. Second, at the level of the individual firm, the anticompetitive effect of centralised bargaining enables firms to charge higher mark-ups, to expand their production and to increase their profits. Despite of the higher wage rate associated with unionisation, equilibrium profits of highly productive firms are then higher under sector-level bargaining than they are in a flexible wage economy. For less productive firms, in contrast, the negative direct effect of higher wages on profits prevails. ${ }^{14}$

In stark contrast to these results, firm-level bargaining reduces average productivity and decreases average output and profits. Firm-level bargaining allows entrants with relatively unfavourable cost draws to remain in the market. Since low productivity firms tend to be small and less profitable, the negative effect on average productivity also reduces average output and profits. The individual firm can again benefit or lose from firm-level bargaining. While enterprises have to pay higher wages compared to the competitive benchmark (with the marginal firm being the exception), surviving firms benefit from the lower equilibrium level of competition. Since firm-specific wages are increasing in productivity, less productive enterprises benefit from firm-level bargaining while more productive firms are hurt. ${ }^{15}$ Decentralised wage agreements thus benefit low productivity firms and harm high productivity firms, while the opposite is true for centralised wage agreements.

\section{Unionization Structures and Welfare}

After the previous section has studied the effect of bargaining structures on productivity and firm performance, this section considers welfare. The indirect utility function in (6) shows that the utility of the representative consumer depends on the price distribution, on product variety and

\footnotetext{
${ }^{14}$ Calculating and comparing equilibrium profits under the different labour market regimes show that gross profits of firms with $c<\left[\theta^{k /(k+2)}-1\right] c_{\max }^{P} /(\theta-1)$ are higher under centralised bargaining than they are in a competitive labour market regime.

${ }^{15}$ The positive (anti-competitive) effect of decentralised bargaining on output and profits dominates for firms with $c>\left[2-4^{1 /(k+2)}\right] c_{\max }^{P}$.
} 
on total income. While the model is well equipped for analysing product prices and variety in the differentiated good sector, it is less appropriate for studying the income effects of unionisation. Not only does the model postulate a constant marginal utility of income, it also abstracts from economy-wide unemployment. Units of labour not demanded by firms in the differentiated good sector are employed in the numeraire sector. Since union bargaining therefore rises pay but does not create unemployment, unionisation increases income by construction. In what follows I therefore focus on the first two determinants of welfare and treat income as exogenous. A welfare analysis with endogenous income is relegated to the Appendix A.1.

\subsection{The Mean and Variance of Prices}

Utility of the representative consumer naturally decreases in the average price level. Moreover, holding the mean of prices constant, an increase in the variance of prices increases utility, as the representative consumer then re-optimises its consumption basket by shifting expenditures to the numeraire good and to lower priced varieties. Using the appropriate wage rate, the profitmaximising price of a variety produced with cost $c$ under labour market regime $\rho=P, U, D$ can be written as:

$$
p^{P}(c)=\frac{1}{2}\left(p_{\max }^{P}+c\right), \quad p^{U}(c)=\frac{1}{2}\left(p_{\max }^{U}+c \theta\right), \quad p^{D}(c)=\frac{1}{2}\left(3 / 2 p_{\max }^{D}+1 / 2 c\right)
$$

The corresponding average price level $\bar{p}^{\rho}$ is given by $\left[\int_{0}^{c_{\max }^{\rho}} p^{\rho}(c) d G(c)\right] / G\left(c_{\max }^{\rho}\right)$, while the variance of prices can be calculated as $\left(\delta_{p}^{\rho}\right)^{2}=\left[\int_{0}^{c_{\max }^{\rho}}\left(p^{\rho}(c)-\bar{p}^{\rho}\right)^{2} d G(c)\right] / G\left(c_{\text {max }}^{\rho}\right)$. Using equations (15) and (24), I then obtain the following first and second moments of the different price distributions:

$$
\begin{aligned}
& \bar{p}^{P}=\frac{2 k+1}{2(k+1)} p_{\text {max }}^{P}, \quad \bar{p}^{U}=\frac{2 k+1}{2(k+1)} p_{\text {max }}^{U}, \quad \bar{p}^{D}=\frac{4 k+3}{4(k+1)} p_{\text {max }}^{D} \\
& \left(\delta_{p}^{P}\right)^{2}=\frac{k\left(p_{\max }^{P}\right)^{2}}{4(k+1)^{2}(k+2)}, \quad\left(\delta_{p}^{U}\right)^{2}=\frac{k\left(p_{\max }^{U}\right)^{2}}{4(k+1)^{2}(k+2)} \cdot\left(\delta_{p}^{D}\right)^{2}=\frac{k\left(p_{\max }^{D}\right)^{2}}{16(k+1)^{2}(k+2)}
\end{aligned}
$$

Given the equilibrium upper price bounds in equations (18) to (20), these moments can be ordered as follows: 
Proposition 3. The orderings of the average price levels, $\bar{p}^{\rho}$, and the variances of prices, $\left(\delta_{p}^{\rho}\right)^{2}$, under the different labour market regimes $\rho=P, U, D$ are as follows:

i. $\bar{p}^{P}<\min \left(\bar{p}^{U}, \bar{p}^{D}\right)$

ii. $\bar{p}^{U}<(>) \bar{p}^{D}$ for $\theta^{k}<(>) 4 \kappa$ with $\kappa=[(4 k+3) /(4 k+2)]^{k+2}>1$,

iii. $\left(\delta_{p}^{U}\right)^{2}>\left(\delta_{p}^{P}\right)^{2}>\left(\delta_{p}^{D}\right)^{2}$.

The average price level is lowest in a flexible wage economy. There are three reasons for why the average price level in a flexible wage economy differs from the mean of prices under centralised wage bargaining. First, a binding sector-wide wage floor increases unit costs $c w$. Second, centralised bargaining also decreases competition in equilibrium. Both factors increase ceteris paribus the profit-maximising price of a firm producing with cost $c$. The selection effect, in contrast, reduces the average price level because it singles out the more productive and thus cheaper firms. Equations (25) show that for any given upper price bound $p_{\max }^{P}=p_{\max }^{U}=p_{\max }$ average prices under the two regimes $P$ and $U$ are exactly identical. The direct effect on unit costs and the selection effect of centralised wage bargaining hence cancel out. Therefore, the anti-competitive effect of unionization prevails and $\bar{p}^{U}$ strictly exceeds $\bar{p}^{P}$ in equilibrium.

Firm-level bargaining also boosts pay and impedes competition (compared to the competitive benchmark) but does not induce tougher selection. As a result, the average price level is larger under decentralised bargaining than with a perfectly competitive labour market even when we abstract from any anti-competitive effect and take $p_{\max }$ as exogenously given. It then also follows that for $\theta^{k}=4$ (and hence for $p_{\max }^{U}=p_{\max }^{D}$ ) $\bar{p}^{U}$ is strictly lower than $\bar{p}^{D}$. The average price level thus tends to be smaller under centralised than under decentralised bargaining, because the former regime singles out more productive firms while the latter does not. Only for large $\theta$, when the intensity of competition under centralised bargaining is very weak, the ordering of $\bar{p}^{U}$ and $\bar{p}^{D}$ can be reversed.

Finally, part iii. of proposition 3 shows that the variance of prices is largest under centralised wage bargaining and lowest under firm-level bargaining. Compared to the flexible labour market regime, centralised wage bargaining increases the average price level and thus the corresponding 
variance increases as well. Firm-level bargaining, in contrast, reduces the variance of prices. Since firm-specific wages increase in productivity, firm-level bargaining compresses the distribution of marginal production costs $c w(c)$. Prices charged by individual firms therefore depend little on idiosyncratic cost draws but are primarily determined by the overall market structure that is common to all firms (see equation 24). Firms with different cost levels therefore set relatively similar prices and the price variance decreases.

\subsection{Product Variety}

Holding constant the distribution of prices, welfare increases in the number of firms and thus in product variety. Using (25), equation (5) can be solved for the number of varieties consumed:

$$
N^{P}=\frac{2(k+1) \gamma}{\eta} \frac{\alpha-p_{\max }^{P}}{p_{\max }^{P}}, \quad N^{U}=\frac{2(k+1) \gamma}{\eta} \frac{\alpha-p_{\max }^{U}}{p_{\max }^{U}}, \quad N^{D}=\frac{4(k+1) \gamma}{\eta} \frac{\alpha-p_{\max }^{D}}{p_{\max }^{D}}
$$

Equations (27) reveal two factors that are of interest for the ordering of product variety under the different labour market regimes. First, variety is positively associated with the 'toughness' of competition. Second, for any given $p_{\max }$ the number of consumed varieties is largest with decentralised wage bargaining. This second finding mirrors proposition 3, according to which the average price level is highest under decentralised wage bargaining (for any given $p_{\max }$ ). A high-price environment allows relatively many firms to survive and thus leads to greater product variety. Accounting for both factors, product variety under the different labour market regimes can be ordered as follows:

Proposition 4. The ordering of the number of consumed varieties, $N^{\rho}$, under the different labour market regimes $\rho=P, U, D$ is as follows:

$$
\begin{aligned}
& \text { i. } N^{P}>N^{U}, \\
& \text { ii. } N^{P}>(<) N^{D} \text { for } p_{\max }^{P}>(<) \varphi \alpha \text { with } 0<\varphi=\left(2 / 4^{1 /(k+2)}-1\right)<1, \\
& \text { iii. } N^{D}>(<) N^{U} \text { for } \theta^{k}>(<) 4 \lambda \text { with } \lambda=\left[\alpha /\left(2 \alpha-4^{1 /(k+2)} p_{\max }^{P}\right)\right]^{k+2}<1 .^{16} \\
& \left.{ }^{16} \lambda<1 \text { follows from } N^{D}>0 \text { (which implies } \alpha-p_{\text {max }}^{D}=\alpha-4^{1 /(k+2)} p_{\max }^{P}>0\right) .
\end{aligned}
$$


The number of consumed varieties is thus strictly larger in a flexible wage economy than under centralised wage bargaining, reflecting the anti-competitive effect of the latter. Decentralised wage bargaining, in contrast, can result in either more or less variety than a competitive labour market. Strong demand for the differentiated varieties relative to the numeraire good (high values of $\alpha$ ) and a relatively large share of firms with an unfavourable cost draw (high values of $k$ ) tend to increase $N^{D}$ relative to $N^{P}$. Finally, the ordering of product variety under decentralised and centralised wage bargaining is ambiguous and depends on the choice of $\theta$. For $\theta^{k}=4$ and thus for $p_{\max }^{U}=p_{\max }^{D}$, however, $N^{D}$ strictly exceeds $N^{U}$.

\subsection{Product Prices vs. Product Variety}

The choice between centralised and decentralised bargaining involves a potential trade-off between product prices and product variety. Holding $p_{\max }$ constant, firm-level bargaining is associated with greater product variety but also with relatively higher prices and lower price variance. Using the results for prices and variety, the indirect utility function in (6) can be rewritten as

$$
\begin{aligned}
U^{P} & =I^{P}+\frac{1}{2 \eta}\left(\alpha-p_{\max }^{P}\right)\left(\alpha-\frac{k+1}{k+2} p_{\max }^{P}\right), \\
U^{U} & =I^{S}+\frac{1}{2 \eta}\left(\alpha-p_{\max }^{U}\right)\left(\alpha-\frac{k+1}{k+2} p_{\max }^{U}\right), \\
U^{D} & =I^{D}+\frac{1}{2 \eta}\left(\alpha-p_{\max }^{D}\right)\left(\alpha-\frac{2 k+3}{2 k+4} p_{\max }^{D}\right) .
\end{aligned}
$$

Given the equilibrium upper price bounds, I can then assess the net effect of the different labour market regimes on consumer welfare (holding income constant).

Proposition 5. Assuming income to be identical across the different labour market regimes, the level of utility gained by the representative consumer under the different labour market regimes $\rho=P, U, D$ can be ordered as follows:

i. $U^{P}>\min \left[U^{U}, U^{D}\right]$,

ii. $U^{U}>(<) U^{D}$ for $\theta^{k}<(>) K$ with $K>4$.

Abstracting from income effects, a competitive labour market results in the highest utility 
level. Unionisation is therefore always only second-best - independent from the level at which wage bargaining takes place. Any positive income effect of unionisation could, of course, change this result. In the Appendix, I show that with endogenous income $U^{U}$ can indeed rise above $U^{P}$ for small values of $\theta>1$. The ordering of welfare under centralised and decentralised wage bargaining is ambiguous and depends on the choice of $\theta$. Since an increase in $\theta$ increases $p_{\max }^{U}$, utility is generally decreasing in $\theta$. As long as the uniform wage rate is not set too high, moving from a centralised to a decentralised bargaining structure implies a loss in consumer welfare. More specifically, $U^{U}$ is strictly larger than $U^{P}$ for $\theta^{k}=4 .{ }^{17}$ The more favourable price distribution induced by centralised bargaining then dominates the negative effect on product variety. It is also informative that $U^{U}$ exceeds $U^{D}$ if $\theta$ is set so as to match the average wage rate earned by workers under decentralised wage bargaining. ${ }^{18}$

\section{Trade Liberalisation and Productivity}

In this section I extend the model setup to a two-country setting and show that the positive effect centralised bargaining has on average productivity can be overturned when firms face international low-wage competition. ${ }^{19}$

\subsection{The Open Economy Setting}

Consider two countries, Home (H) and Foreign (F), that are identical except for their labour market regimes. The representative cosumer in both countries share the same preferences that result in the inverse demand function in (3). National goods markets are segmented and firms incur per-unit iceberg trade costs, i.e. exporters have to ship $t>1$ units of the good in order for one unit to arrive at the export destination.

From equation (5) the upper price bound for positive demand in market $i=H, F, p_{\text {max }}^{i}$, is given

\footnotetext{
${ }^{17}$ This directly follows from $(k+1) /(k+2)<(2 k+3) /(2 k+4)$ for $k \geq 1$.

${ }^{18}$ The average wage rate under decentralised wage bargaining can be calculated by dividing the total wage bill in the differentiated good sector, $N\left[\int_{0}^{c_{\max }^{D}} c^{D} q^{D}(c) d G(c)\right] / G\left(c_{\max }^{D}\right)$, by total employment, $N\left[\int_{0}^{c_{\max }^{D}} c^{D} q^{D}(c) w^{D}(c) d G(c)\right] / G\left(c_{\max }^{D}\right)$. This yields $(k+1) / k$. For this choice of $\theta$ the upper price bound is strictly lower with centralised than with decentralised bargaining.

${ }^{19}$ In the Appendix A.2, I briefly show that with symmetric labour market regulations the main results derived in the previous sections continue to hold in the open economy setting.
} 
by

$$
p_{\max }^{i}=\frac{1}{\eta N^{i}+\gamma}\left(\gamma \alpha+\eta N^{i} \bar{p}^{i}\right)
$$

where $N^{i}$ is the total number of firms selling in market $i$ and $\bar{p}_{i}$ denotes their average price level. Since markets are segmented and marginal production costs are constant, firms separately maximise their profits earned from domestic and export activities. Let $q_{L}^{i}(c)$ and $q_{X}^{i}(c)$ denote the profit-maximising levels of output sold respectively in the local and in the export market by a firm producing in country $i$ with cost $c$. The corresponding profit-maximising prices are $p_{L}^{i}(c)$ and $p_{X}^{i}(c)$. Profits earned from domestic and export sales are then given by

$$
\begin{aligned}
\Pi_{L}^{i}(c) & =\left[p_{L}^{i}(c)-c w^{i}\right] q_{L}^{i}(c), \\
\Pi_{X}^{i}(c) & =\left[p_{X}^{i}(c)-c t w^{i}\right] q_{X}^{i}(c),
\end{aligned}
$$

where $w^{i}$ is the wage rate in country $i$. The corresponding first order conditions read

$$
\begin{aligned}
q_{L}^{i}(c) & =\frac{1}{\gamma}\left[p_{L}^{i}(c)-c w^{i}\right], \\
q_{X}^{i}(c) & =\frac{1}{\gamma}\left[p_{X}^{i}(c)-c t w^{i}\right] .
\end{aligned}
$$

Using the demand system in (4), the profit-maximising price and output choices then satisfy

$$
\begin{aligned}
& p_{L}^{i}(c)=\frac{1}{2}\left(p_{\text {max }}^{i}+c w^{i}\right), p_{X}^{i}(c)=\frac{1}{2}\left(p_{\text {max }}^{j}+c t w^{i}\right) \\
& q_{L}^{i}(c)=\frac{1}{2 \gamma}\left(p_{\text {max }}^{i}-c w^{i}\right), q_{X}^{i}(c)=\frac{1}{2 \gamma}\left(p_{\text {max }}^{j}-c t w^{i}\right) .
\end{aligned}
$$

These choices yield the following maximised profit levels:

$$
\begin{aligned}
\Pi_{L}^{i}(c) & =\frac{1}{4 \gamma}\left(p_{\text {max }}^{i}-c w^{i}\right)^{2} \\
\Pi_{X}^{i}(c) & =\frac{1}{4 \gamma}\left(p_{\max }^{j}-c t w^{i}\right)^{2}
\end{aligned}
$$

A firm only chooses to sell in a market if it earns non-negative profits. This leads to (separate) cost cut-off levels for either market. Let $c_{L}^{i}$ and $c_{X}^{i}$ denote the upper cost bounds of country $i$ 's 
firms for selling in the local and in the export market, respectively. From equations (38) and (39) these cut-offs must satisfy

$$
\begin{aligned}
c_{L}^{i} & =\frac{p_{\max }^{i}}{w^{i}}, \\
c_{X}^{i} & =\frac{p_{\max }^{j}}{t w^{i}} .
\end{aligned}
$$

Notice that the cut-off levels of local producers in $i$ and exporters from $j$ to $i$ are related through $c_{X}^{j}=\left(w^{i} c_{L}^{i}\right) /\left(t w^{j}\right)$. Higher trade barriers make it harder for exporters to break even relative to domestic firms. Cross-country differences in the wage level can mitigate or amplify this effect. As in the closed economy setting, each start-up has to make an initial investment. Its cost level is then drawn from a common and known distribution. Unrestricted entry in both countries ensures that expected gross profits, which consist of expected profits from domestic and export activities, are driven down to the fixed entry cost. In order to isolate the effect of different labour market regulations, I assume that new entrants in Home and Foreign draw their cost level from the same cost distribution $G(c)=\left(c / c_{M}\right)^{k}$ and have to pay the same fixed entry cost $f_{E}$. The free entry condition for country $i$ can then be written as

$$
\int_{0}^{c_{L}^{i}} \Pi_{L}^{i}(c) d G(c)+\int_{0}^{c_{X}^{i}} \Pi_{X}^{i}(c) d G(c)=f_{E}
$$

Finally, labour market regulations in Home and Foreign differ. For the sake of brevity, I only consider one specific scenario: firms in Home are subjected to centralised wage bargaining, while the labour market in Foreign is perfectly competitive. ${ }^{20}$ The wage rate in Home therefore equals $w^{H}=\theta$ and is strictly above the unit wage that prevails in Foreign.

\footnotetext{
${ }^{20}$ As will become apparent in the next subsection, the main mechanism at work in an open but not in a closed economy setting is a relocation effect. Start-ups prefer to enter in a low- rather than in a high-wage country. Since centralised and decentralised wage bargaining both increase expected wage payments, the relocation effect is present under both bargaining regimes.
} 


\subsection{Trade, Labour Market Regulations, and Productivity}

I start with rewriting the upper cost bounds for both markets by substituting the respective wage rate into (40) and (41):

$$
\begin{aligned}
c_{L}^{H} & =\frac{p_{\max }^{H}}{\theta}, c_{X}^{H}=\frac{p_{\max }^{F}}{t \theta}, \\
c_{L}^{F} & =p_{\max }^{F}, c_{X}^{F}=\frac{p_{\max }^{H}}{t} .
\end{aligned}
$$

Likewise, profits from domestic and exporting activities of firms located in Home and Foreign, respectively, can be written as

$$
\begin{aligned}
\Pi_{L}^{H}(c) & =\frac{1}{4 \gamma}\left(p_{\max }^{H}-c \theta\right)^{2}, \Pi_{X}^{H}(c)=\frac{1}{4 \gamma}\left(p_{\max }^{F}-c t \theta\right)^{2}, \\
\Pi_{L}^{F}(c) & =\frac{1}{4 \gamma}\left(p_{\max }^{F}-c\right)^{2}, \Pi_{X}^{F}(c)=\frac{1}{4 \gamma}\left(p_{\max }^{H}-c t\right)^{2} .
\end{aligned}
$$

Suppose for the moment that $p_{\max }^{H}$ and $p_{\max }^{F}$ are exogenously given and identical. Analogous to the findings for the closed economy setting, centralised bargaining then induces tougher selection; the cost cut-off levels for firms located in Home are ceteris paribus decreasing in $\theta$. For any given level of $p_{\max }$ centralised bargaining also depresses firm profits. Inspecting the maximised profit values in (45) and (46) furthermore shows that for $\theta \geq t$ firms are strictly better off by locating in Foreign rather than in Home (as they can supply both markets at lower costs when based in Foreign). To ensure a positive mass of domestic entrants in Home, I will therefore assume that $\theta$ is strictly smaller than $t$. The free entry condition in (42) then holds as an equality.

To solve for the endogenous cost cut-offs levels, use (40) and (41) to rewrite profits as $\Pi_{L}^{H}(c)=$ $\frac{\theta^{2}}{4 \gamma}\left(c_{L}^{H}-c\right)^{2}, \Pi_{X}^{H}(c)=\frac{\theta^{2} t^{2}}{4 \gamma}\left(c_{X}^{H}-c\right)^{2}$ and $\Pi_{L}^{F}(c)=\frac{1}{4 \gamma}\left(c_{L}^{F}-c\right)^{2}, \Pi_{X}^{F}(c)=\frac{t^{2}}{4 \gamma}\left(c_{X}^{F}-c\right)^{2}$. Given these expressions, the zero profit conditions can be written as

$$
\left(c_{L}^{H}\right)^{k+2}+t^{2}\left(c_{X}^{H}\right)^{k+2}=\frac{\gamma \varphi}{\theta^{2}}, \quad\left(c_{L}^{F}\right)^{k+2}+t^{2}\left(c_{X}^{F}\right)^{k+2}=\gamma \varphi,
$$


where $\varphi \equiv(k+1)(k+2)\left(c_{M}\right)^{k} f_{E}$. Using $c_{X}^{H}=c_{L}^{F} /(t \theta)$ and $c_{X}^{F}=\theta c_{L}^{H} / t$, these conditions can be rewritten as a system of two equations in the two unknowns $c_{L}^{H}, c_{L}^{F}$ :

$$
\left(c_{L}^{H}\right)^{k+2}+\tau\left(\frac{c_{L}^{F}}{\theta}\right)^{k+2}=\frac{\gamma \varphi}{\theta^{2}}, \quad\left(c_{L}^{F}\right)^{k+2}+\tau\left(\theta c_{L}^{H}\right)^{k+2}=\gamma \varphi
$$

with $\tau \equiv t^{-k}$ being an inverse measure of trading costs. Solving this system yields

$$
c_{L}^{H}=\left[\frac{2 \gamma \varphi\left(\theta^{k}-\tau\right)}{\left(1-\tau^{2}\right) \theta^{k+2}}\right]^{\frac{1}{k+2}}, \quad c_{L}^{F}=\left[\frac{2 \gamma \varphi\left(1-\tau \theta^{k}\right)}{1-\tau^{2}}\right]^{\frac{1}{k+2}} .
$$

The cost cut-offs then pin down the upper price bounds through (43) and (44).

Before comparing the resulting equilibrium cut-off levels and the corresponding upper price bounds for Home and Foreign, I analyse first how these cost thresholds change as trade barriers are dismantled. Calculating the elasticities of $c_{L}^{i}$ with respect to $\tau$ for $i=H, F$ gives

$$
\begin{aligned}
\frac{\partial c_{L}^{H}}{\partial \tau} \frac{\tau}{c_{L}^{H}} & =\frac{\tau\left(2 \tau \theta^{k}-\tau^{2}-1\right)}{(k+2)\left(1-\tau^{2}\right)\left(\theta^{k}-\tau\right)} \\
\frac{\partial c_{L}^{F}}{\partial \tau} \frac{\tau}{c_{L}^{F}} & =\frac{\tau\left(2 \tau-\left(1+\tau^{2}\right) \theta^{k}\right)}{(k+2)\left(1-\tau^{2}\right)\left(1-\tau \theta^{k}\right)}
\end{aligned}
$$

Analysing these elasticities establishes

Proposition 6. Trade liberalization (i.e. an increase in $\tau$ ) will always lower the cost cut-off in Foreign. In contrast, trade liberalisation will increase (decrease) the cut-off in Home for $\theta^{k}>\left(1+\tau^{2}\right) / 2 \tau$. Furthermore, the elasticity of $c_{L}^{i}$ with respect to $\tau$ is strictly larger in Home than its is in Foreign, and it is increasing in $\theta$ in the former country while it is decreasing in $\theta$ in the latter.

Proof. The proof is relegated to the Appendix A.3.

With cross-country differences in labour market regimes trade liberalisation has to two distinct effects on the cost cut-offs. First, lower trade barriers increase import competition in both markets. As a result, demand price elasticities increase, the least productive firms are forced to exit and $c_{L}^{H}$ and $c_{L}^{F}$ decrease. This is the mechanism highlighted by Melitz and Ottaviano 
(2008). If wages were identical across countries, dismantling trade barriers would always lower the cost cut-offs in both countries. With cross-country wage differentials, however, trade liberalisation has an additional 'relocation' effect. As trade barriers fall, wage differentials become an increasingly important criterion of location. Consequently, the number of entrants and thus the intensity of competition increases in the low wage country and decreases in the high wage country. The relocation effect is larger the higher the cross-country wage differential is. When the wage rate in Home is sufficiently high relative to the level of trading barriers, the relocation effect dominates and trade liberalisation strictly increases the cost cut-off in Home. Given (43), it then also follows that the intensity of competition in market $H$ decreases ( $p_{\max }^{H}$ increases). Proposition 6 thus shows that in an open economy setting the selection effect of centralised bargaining, described at length for the closed economy setting, is not only thwarted by the anti-competitive effect of higher wages but also by a relocation effect. For hight trade costs the selection effect prevails and the cost cut-off is lower in Home than in Foreign. However, the ordering can be reversed as trade barriers are dismantled. This is demonstrated in

Proposition 7. The orderings of the cut-off levels, $c_{L}^{i}$, and the upper price bounds, $p_{\text {max }}^{i}$, for country $i=H, F$ are as follows:

i. $c_{L}^{H}>(<) c_{L}^{F}$ for $\tau>(<)\left(\theta^{k+2}-\theta^{k}\right) /\left(\theta^{2 k+2}-1\right)$,

ii. $p_{\max }^{H}>p_{\max }^{F}$.

Having explicitly calculated the cost cut-off levels and the corresponding upper price bounds, I can now assess firm-level performance. For doing so, notice first that in some market $i$ the cost of domestic firms $c w^{i} \in\left[0, c_{L}^{i}\right]$ and the delivered cost of exporters $t c w^{j} \in\left[0, t c_{X}^{j}\right]=\left[0, c_{L}^{i}\right]$ have identical distributions over the same support, as given by $G(c)=\left(c / c_{L}^{i}\right)^{k}$. Average firm performance of local firms in $i$ and exporters from $j$ to $i$ are then also identical, since their output and profit levels depend only on (delivered) costs and on the common upper price bound 
$p_{\text {max }}^{i}$. More specifically, I find that

$$
\begin{aligned}
& \bar{q}_{L}^{H}=\bar{q}_{X}^{F}=\frac{p_{\max }^{H}}{2 \gamma(k+1)}, \quad \bar{q}_{L}^{F}=\bar{q}_{X}^{H}=\frac{p_{\max }^{F}}{2 \gamma(k+1)}, \\
& \bar{\Pi}_{L}^{H}=\bar{\Pi}_{X}^{F}=\frac{\left(p_{\max }^{H}\right)^{2}}{2 \gamma(k+1)(k+2)}, \quad \bar{\Pi}_{L}^{F}=\bar{\Pi}_{X}^{H}=\frac{\left(p_{\max }^{F}\right)^{2}}{2 \gamma(k+1)(k+2)} .
\end{aligned}
$$

Given Proposition 7ii., these average performance measures can be ordered as follows:

Proposition 8. Output sold in the local market, $\bar{q}_{L}^{i}$, and profits earned from domestic sales, $\bar{\Pi}_{L}^{i}$, are on average higher for firms located in Home. Thus, the following orderings are established:

i. $\bar{q}_{L}^{H}=\bar{q}_{X}^{F}>\bar{q}_{L}^{F}=\bar{q}_{X}^{H}$,

ii. $\bar{\Pi}_{L}^{H}=\bar{\Pi}_{X}^{F}>\bar{\Pi}_{L}^{F}=\bar{\Pi}_{X}^{H}$.

Average profits and sales are thus higher in Home, the country characterised by centralised wage bargaining. This result resembles proposition 2 derived in the closed economy setting. However, in a global world economy not only domestic firms but also foreign enterprises that export from Foreign to Home benefit from the relatively low intensity of competition in Home. Likewise, both local enterprises based in Foreign and exporters from Home to Foreign suffer from the intense competition in Foreign.

Finally, I assess cross-country differences in product variety and in the mean of prices; income is considered in the Appendix A.4. The average price of a variety sold in country $i$ reflects prices charged by both local firms, $p_{L}^{i}(c)$, and by exporting firms from $j, p_{X}^{j}(c)$. I previously described that the cost of domestic firms and the delivered cost of exporters share the same distribution. This also leads to matching price distributions. The average price of domestic firms in a country and of exporters to that country are thus identical and given by $\bar{p}^{i}=\left[\int_{0}^{c_{L}^{i}} p_{L}^{i} d G(c)\right] / G\left(c_{L}^{i}\right)$. Combining this with equation (36) yields:

$$
\bar{p}^{H}=\frac{2 k+1}{2 k+2} p_{\max }^{H}, \quad \bar{p}^{F}=\frac{2 k+1}{2 k+2} p_{\max }^{F}
$$

The number of varieties sold in each market can then be calculated by substituting (54) into 
(31) and rearranging. Doing so gives

$$
N^{H}=\frac{2(k+1) \gamma}{\eta} \frac{\alpha-p_{\max }^{H}}{p_{\max }^{H}}, \quad N^{F}=\frac{2(k+1) \gamma}{\eta} \frac{\alpha-p_{\max }^{F}}{p_{\max }^{F}} .
$$

Given propositions 6 and 7, I can conclude:

Proposition 9. The number of varieties in Foreign is strictly higher and their average price strictly lower than in Home. Trade liberalisation increases product variety and decreases the average price level in Foreign. In Home, trade liberalisation increases (decreases) variety and decreases (increases) average prices for $\theta^{k}<(>)\left(1+\tau^{2}\right) / 2 \tau$.

The flexible wage country thus features strictly lower prices and higher product variety than the high wage country. These orderings thus correspond to the findings for the closed economy. More interestingly, trade liberalisation, by weakening competition, can actually decrease product variety and increase prices in the high wage country. This result is squarely at odds with the usual finding that bilateral trade liberalisation increases consumer welfare by intensifying import competition. In contrast, for the low wage country the conventional wisdom holds and economic integration increases product variety and lowers prices.

Since the results for product variety and average prices in the open economy are identical to the closed-economy case, welfare can be written in a way identical to (28) and (29):

$$
\begin{aligned}
U^{H} & =I^{H}+\frac{1}{2 \eta}\left(\alpha-p_{\max }^{H}\right)\left(\alpha-\frac{k+1}{k+2} p_{\max }^{H}\right), \\
U^{U} & =I^{F}+\frac{1}{2 \eta}\left(\alpha-p_{\max }^{F}\right)\left(\alpha-\frac{k+1}{k+2} p_{\max }^{F}\right) .
\end{aligned}
$$

As the intensity of competition is higher in Foreign than it is in Home, welfare is also strictly higher in the low wage economy (abstracting again from income effects). Furthermore, trade liberalisation increases welfare in Foreign but may decrease welfare in Home. 


\section{Conclusion}

This paper has studied how the level at which collective wage contracts are negotiated affects firm productivity, firm performance, and consumer welfare. While centralised bargaining induces tougher selection among heterogeneous producers and thus increases average productivity, firmlevel bargaining allows less productive entrants to stay in the market, as inter-firm productivity differences will find consideration in firm-level wage settlements. Centralised bargaining also results in higher average output and in higher profit levels than either decentralised bargaining or a competitive labour market. Moreover, I have shown that moving from centralised to decentralised bargaining is not necessarily welfare-improving. While firm-level bargaining tends to increase product variety, it also entails higher product prices.

The paper has also highlighted that the effects of national labour market regulations may change when goods markets become global. In a two-country model of trade between a rigid-wage and a flexible-wage economy, centralised bargaining still induces tougher selection. Yet unionisation also induces firms to enter in the low- rather than in the high-wage country. This reduces competition and average productivity in the latter. As trade barriers fall, cross-country wage differentials become an increasingly important criterion for firms in their choice of where to locate. Trade liberalisation can thus reduce competition, lower productivity, and depress welfare in the unionised economy.

The predictions of the theoretical model can be useful in guiding future empirical work on the relation between unionisation, productivity, and firm performance. Existing empirical studies mainly seek to identify the effect of a change in unionisation status on an individual firm in a given industry. ${ }^{21} \mathrm{My}$ work suggests that a more complete analysis requires complementary evidence on the relation between unionisation structures and average firm performance at the industry level that also accounts for the endogeneity of the market structure.

\footnotetext{
${ }^{21}$ Evidence on the link between unionisation and productivity is inconclusive, while the bulk of studies find unionised workplaces to be less profitable than non-unionised ones (cf. Metcalf, 2003, and Hirsch, 2004, for recent surveys of the literature). These findings are not at odds with the theoretical predictions of the present paper. Holding the market structure constant, collective bargaining unambiguously decreases firm-level profits.
} 


\section{References}

Campbell, J. R., Hopenhayn, H. A., 2005. Market size matters. Journal of Industrial Economics $53(1), 1-25$.

Del Gatto, M., Mion, G., Ottaviano, G. I. P., 2006. Trade integration, firm selection and the costs of non-europe. CEPR Discussion Papers 5730, C.E.P.R. Discussion Papers.

Grout, P. A., 1984. Investment and wages in the absence of binding contracts: A nash bargining approach. Econometrica 52 (2), 449-60.

Haucap, J., Wey, C., 2004. Unionisation structures and innovation incentives. Economic Journal 114 (494), C149-C165.

Hirsch, B. T., 2004. What do unions do for economic performance? Journal of Labor Research $25(3), 415-456$.

Melitz, M. J., Ottaviano, G. I. P., 2008. Market size, trade, and productivity. Review of Economic Studies 75 (1), 295-316.

Metcalf, D., 2003. International handbook of trade unions. Cheltenham: Edward Elgar, Ch. Unions and productivity, financial performance and investment: international evidence, pp. $118-171$.

Moene, K. O., Wallerstein, M., 1997. Pay inequality. Journal of Labor Economics 15 (3), 403-30.

Rehn, G., 1952. Wages policy under full employment. London: W. Hodge, Ch. The Problem of Stability: An Analysis of some Policy Proposals.

Tauman, Y., Weiss, Y., 1987. Labor unions and the adoption of new technology. Journal of Labor Economics 5 (4), 477-501.

Tybout, J. R., 2003. Handbook of international trade. Oxford: Basil-Blackwell, Ch. Plant- and Firm-level Evidence on the 'New' Trade Theories, pp. 388-415. 
Ulph, A., Ulph, D., 2001. Strategic innovation with complete and incomplete labour market contracts. Scandinavian Journal of Economics 103 (2), 265-82.

Ulph, A. M., Ulph, D. T., 1994. Labour markets and innovation: Ex-post bargaining. European Economic Review 38 (1), 195-210.

van der Ploeg, F., 1987. Trade unions, investment, and employment. European Economic Review $31,1465-92$. 


\section{A Appendix}

\section{A.1 Endogenous Income and Welfare in the Closed Economy Setting}

In this subsection, I endogenise income. Overall profits net of entry costs, i.e. gross profits of all surviving firms minus the start up costs of all entrants, are zero. Wages are therefore the only source of income in the model. The wage bill of the differentiated product sector can be calculated by multiplying the average wage bill of a single firm, $\bar{W}^{\rho}=\left[\int_{0}^{c_{m a x}^{\rho}} c^{\rho} q^{\rho}(c) w^{\rho}(c) d G(c)\right] / G\left(c_{\max }^{\rho}\right)$ by the total number of firms, $N^{\rho}$. Units of labour not demanded by firms in the differentiated good sector are employed in the numeraire sector and earn the competitive wage rate of one. Labour income in the numeraire good sector thus equals total labour supply minus the units of labour employed in the differentiated good sector. The latter can be found by multiplying the average labour demand of a single firm, $\bar{E}^{\rho}=\left[\int_{0}^{c_{\max }^{\rho}} c^{\rho} q^{\rho}(c) d G(c)\right] / G\left(c_{\max }^{\rho}\right)$, by the total number of firms. Summarising the above, total income $I^{\rho}$ under labour market regime $\rho=P, U, D$ is given by $\overline{W B}{ }^{\rho} N^{\rho}+\left(L-\bar{E}^{\rho} N^{\rho}\right)$. Rearranging gives

$$
I^{\rho}=L+\left(\frac{\bar{W}^{\rho}}{\bar{E}^{\rho}}-1\right) \bar{E}^{\rho} N^{\rho} .
$$

Equation (58) demonstrates that total income can be apportioned into labour supply $L$, which equals the total wage bill in case all workers were employed in the numeraire good sector, plus the rent earned by labour in the differentiated good sector. The rent increases with the average wage differential between the two sectors $\left(\bar{W}^{\rho} / \bar{E}^{\rho}-1\right)$ and with employment in the differentiated product sector $\left(\bar{E}^{\rho} N^{\rho}\right)$.

With a perfectly competitive labour market the inter-sectoral wage differential is zero and income just equals $L$. With centralised bargaining the wage differential is $\theta-1$ and firm-level bargaining elicits an average differential of $(k+1) / k-1$. Multiplying the respective wage differential by the corresponding employment level and substituting into (58) yields:

$$
I^{P}=L, I^{U}=L+\frac{k(\theta-1)}{\theta} \frac{\left(\alpha-p_{\max }^{U}\right) p_{\max }^{U}}{\eta(k+2)}, I^{D}=L+\frac{\left(\alpha-p_{\max }^{D}\right) p_{\max }^{D}}{\eta(k+2)}
$$


Given the full employment assumption and the fact that bargaining rises pay, labour income under both bargaining regimes exceeds income in the flexible wage economy. The ordering of $I^{U}$ and $I^{D}$ is, however, ambiguous and depends on the rent earned by labour under the the two bargaining modes. Very low and very high values of $\theta$ cause the rent earned under centralised bargaining to approach zero (and $I^{U}$ to fall below $I^{D}$ ). Small values of $\theta$ level the inter-sectoral wage differential, while very large values marginalise employment in the differentiated good sector. For intermediate levels of $\theta$, however, labour income under centralised wage bargaining can exceed income under firm-level bargaining. Consider exemplarily the case of $\theta^{k}=4$ (and hence $\left.p_{\max }^{U}=p_{\max }^{D}\right){ }^{22}$ Income under centralised bargaining is then larger (smaller) than income under firm-level bargaining for $k>2(k<2)$. While the wage differential is strictly larger under regime $U$ at $\theta^{k}=4,{ }^{23}$ more firms are active under regime $D$ (cf. proposition 4ii.). Finally, average labour demand per firm, $\bar{E}$, is larger (smaller) under centralised bargaining for $k>2$ $(k<2) \cdot{ }^{24}$

With endogenous income, utility under labour market regime $\rho, U^{\rho}$ can be written as:

$$
\begin{aligned}
U^{P} & =L+\frac{1}{2 \eta}\left(\alpha-p_{\text {max }}^{P}\right)\left(\alpha-\frac{k+1}{k+2} p_{\max }^{P}\right), \\
U^{U} & =L+\frac{1}{2 \eta}\left(\alpha-p_{\max }^{U}\right)\left(\alpha-\frac{2 k-\theta(k-1)}{\theta(k+2)} p_{\max }^{U}\right), \\
U^{D} & =L+\frac{1}{2 \eta}\left(\alpha-p_{\max }^{D}\right)\left(\alpha-\frac{2 k-1}{2 k+4} p_{\max }^{D}\right) .
\end{aligned}
$$

For small values of $\theta$ centralised bargaining can actually result in higher welfare than a competitive labour market. To see this possibility, notice that $U^{P}$ and $U^{U}$ converge as $\theta$ approaches the competitive wage rate of one. It then remains to be shown that at $\theta=1$ utility under centralised bargaining can be increasing in $\theta$. Differentiating $U^{U}$ with respect to $\theta$ gives

$$
\frac{\partial U^{U}}{\partial \theta}=-\Upsilon\left[2 p_{\max }^{U}(2+k(\theta-1)-\theta)+\alpha(3 \theta-4)\right],
$$

\footnotetext{
${ }^{22}$ More generally, $I^{U}$ is larger (smaller) than $I^{D}$ for $k(\theta-1)\left(\alpha-p_{\max }^{U}\right)>(<)\left(4 \theta^{2}\right)^{1 /(k+2)}\left(\alpha-p_{\max }^{D}\right)$.

${ }^{23} 4^{1 / k}$ is strictly larger than $(k+1) / k$ for $k \geq 1$.

${ }^{24}$ Calculating average labour demand explicitly gives $\bar{E}^{U}=\left(k\left(p_{\max }^{U}\right)^{2}\right) /(2 \nu \theta)$ and $\bar{E}^{D}=\left(k\left(p_{\max }^{D}\right)^{2}\right) /(4 \nu)$ with $\nu=\gamma(k+1)(k+2)$. For $\theta^{k}=4 \bar{E}^{U}$ is larger than $\bar{E}^{D}$ provided that $4^{1 / k}<2$.
} 
where $\Upsilon$ is strictly positive. The sign of (63) is indeed indeterminate for $1 \leq \theta<4 / 3$ (but strictly negative thereafter). It then follows that centralised bargaining can in principle improve welfare by increasing income and the variance of prices.

\section{A.2 The Open Economy Setting with Symmetric Labor Market Regimes}

In this subsection, I consider the two country setting with symmetric labour market regulations. Since the two trading partners Home and Foreign are then identical, I drop the country superscript $i=H, F$. Instead, the superscript $\rho=P, U$ is used to distinguish between country pairs sharing a perfectly competitive labour market and a centralised wage bargaining regime, respectively. Given the symmetry of the model, I shall only present equations for Home. Analogous equations exist for Foreign as well.

Using (40) and (41), for each country pair $\rho=P, U$ firm-level profits (34) and (35) can be rewritten as

$$
\begin{aligned}
& \Pi_{L}^{P}(c)=\frac{1}{4 \gamma}\left(c_{L}^{P}-c\right)^{2}, \Pi_{X}^{P}(c)=\frac{t^{2}}{4 \gamma}\left(c_{X}^{P}-c\right)^{2} \\
& \Pi_{L}^{U}(c)=\frac{\theta^{2}}{4 \gamma}\left(c_{L}^{U}-c\right)^{2}, \Pi_{X}^{U}(c)=\frac{t^{2} \theta^{2}}{4 \gamma}\left(c_{X}^{U}-c\right)^{2}
\end{aligned}
$$

The corresponding free entry conditions are then given by:

$$
\left(c_{L}^{P}\right)^{k+2}+t^{2}\left(c_{X}^{P}\right)^{k+2}=2 \gamma \varphi, \quad\left(c_{L}^{U}\right)^{k+2}+t^{2}\left(c_{X}^{U}\right)^{k+2}=\frac{2 \gamma \varphi}{\theta^{2}}
$$

with $\varphi \equiv(k+1)(k+2)\left(c_{M}\right)^{k} f_{E}$. Using $c_{X}^{\rho}=c_{L}^{\rho} / t$, these equations can then be solved for the cost thresholds $c_{L}^{\rho}$ and the corresponding upper price bounds:

$$
\begin{aligned}
& c_{L}^{P}=p_{\max }^{P}=\left(\frac{2 \gamma \varphi}{1+\rho}\right)^{1 /(k+2)}, \\
& c_{L}^{U}=\frac{p_{\max }^{U}}{\theta}=\left(\frac{1}{\theta^{2}}\right)^{1 /(k+2)}\left(\frac{2 \gamma \varphi}{1+\rho}\right)^{1 /(k+2)} .
\end{aligned}
$$

Inspecting these expressions shows that - analogous to the closed economy setting - the cut-off level $c_{L}^{P}$ strictly exceeds $c_{L}^{U}$ and the corresponding price bound $p_{\max }^{P}$ falls short of $p_{\max }^{U}$. With 
symmetric labour markets the orderings of both the cost cut-offs and the upper price bounds established in the closed economy model carry over to the open economy setting. Furthermore, without cross-country differences in the wage rate, trade liberalisation just increases import competition and thus always induces tougher selection among heterogeneous producers.

\section{A.3 Proof of Proposition 6}

Proof. For a positive mass of entrants in Home, $\theta$ has to be smaller than $t$. This also implies that $\theta^{k}-\tau$ and $1-\tau \theta^{k}$ (with $\tau=1 / t^{k}$ ) are both positive in sign. The elasticity of $c_{L}^{H}$ with respect to $\tau$ is then positive (negative) for $\theta^{k}>(<)\left(1+\tau^{2}\right) / 2 \tau$. The corresponding elasticity of Foreign is negative for $\theta^{k}>2 \tau /(\tau+1)$. This latter condition is always fulfilled for the relevant parameter values $t>\theta>1,0<\tau<1$. Furthermore, differentiating the two elasticities with respect to $\tau$ gives

$$
\begin{aligned}
\partial\left(\frac{\partial c_{L}^{H}}{\partial \tau} \frac{\tau}{c_{L}^{H}}\right) / \partial \tau & =\tau /\left[(k+2)\left(1-\tau^{2}\right)\left(\theta^{k}-\tau\right)^{2}\right]>0 \\
\partial\left(\frac{\partial c_{L}^{F}}{\partial \tau} \frac{\tau}{c_{L}^{F}}\right) / \partial \tau & =\tau\left(\tau^{2}-1\right) /\left[(k+2)\left(1-\tau^{2}\right)\left(1-\tau \theta^{k}\right)^{2}\right]<0
\end{aligned}
$$

where the respective signs directly follow from $\tau<1$.

\section{A.4 Endogenous Income in the Open Economy Setting}

As in the closed economy setting, the unit wage in Foreign implies $I^{F}=L$. Income in Home, on the other hand, is given by $L+(\theta-1) E^{H}$ where $E^{H}$ are the units of labour employed by firms producing differentiated varieties in Home. Production destined for the domestic market requires on average

$$
\bar{E}_{L}^{H}=\frac{k p_{\max }^{H}}{2 \gamma(k+1)(k+2) \theta}
$$

units of labour. In addition, exporting firms will demand

$$
\bar{E}_{X}^{H}=\frac{k p_{\max }^{F}}{2 \gamma(k+1)(k+2) t \theta}
$$


labour units for their export activities.

Total employment can then be found by multiplying these average employment measures by the number of non-exporters and exporters in Home, respectively. Given a positive mass of entrants $N_{E}^{H}$ in country $H$, there are $G\left(c_{L}^{H}\right) N_{E}^{H}$ non-exporters and $G\left(c_{X}^{H}\right) N_{E}^{H}$ exporters producing in $H$. In order to obtain $N_{E}^{H}$, I split the total number of firms selling in market $i, N^{i}$, into domestic producers in $i, G\left(c_{L}^{i}\right) N_{E}^{i}$, and exporters from $j$ to $i, G\left(c_{X}^{j}\right) N_{E}^{j}$. The conditions $G\left(c_{L}^{i}\right) N_{E}^{i}+$ $G\left(c_{X}^{j}\right) N_{E}^{j}=N^{i}$ (holding for each country $i=H, F$ ) can then be solved for the number of entrants in both markets:

$$
\begin{aligned}
N_{E}^{H} & =\frac{\left(c_{M}\right)^{k}}{1-\tau^{2}}\left[\frac{1}{\left(c_{D}^{H}\right)^{k}} N^{H}-\frac{\tau \theta^{k}}{\left(c_{D}^{F}\right)^{k}} N^{F}\right] \\
& =\frac{2\left(c_{M}\right)^{k} \gamma(k+1)}{\left(1-\tau^{2}\right) \eta}\left[\frac{\alpha-c_{D}^{H} \theta}{\left(c_{D}^{H}\right)^{k+1} \theta}-\frac{\tau \theta^{k}\left(\alpha-c_{D}^{F}\right)}{\left(c_{D}^{F}\right)^{k+1}}\right], \\
N_{E}^{F} & =\frac{\left(c_{M}\right)^{k}}{1-\tau^{2}}\left[\frac{1}{\left(c_{D}^{F}\right)^{k}} N^{F}-\frac{\tau \theta^{k}}{\left(c_{D}^{H}\right)^{k}} N^{H}\right] \\
& =\frac{2\left(c_{M}\right)^{k} \gamma(k+1)}{\left(1-\tau^{2}\right) \eta}\left[\frac{\alpha-c_{D}^{F}}{\left(c_{D}^{F}\right)^{k+1}}-\frac{\tau\left(\alpha-c_{D}^{H} \theta\right)}{\left(\theta c_{D}^{H}\right)^{k+1}}\right] .
\end{aligned}
$$




\section{SFB 649 Discussion Paper Series 2009}

For a complete list of Discussion Papers published by the SFB 649, please visit http://sfb649. wiwi.hu-berlin.de.

001 "Implied Market Price of Weather Risk" by Wolfgang Härdle and Brenda López Cabrera, J anuary 2009.

002 "On the Systemic Nature of Weather Risk" by Guenther Filler, Martin Odening, Ostap Okhrin and Wei Xu, January 2009.

003 "Localized Realized Volatility Modelling" by Ying Chen, Wolfgang Karl Härdle and Uta Pigorsch, January 2009.

004 "New recipes for estimating default intensities" by Alexander Baranovski, Carsten von Lieres and André Wilch, January 2009.

005 "Panel Cointegration Testing in the Presence of a Time Trend" by Bernd Droge and Deniz Dilan Karaman Örsal, January 2009.

006 "Regulatory Risk under Optimal Incentive Regulation" by Roland Strausz, January 2009.

007 "Combination of multivariate volatility forecasts" by Alessandra Amendola and Giuseppe Storti, January 2009.

008 "Mortality modeling: Lee-Carter and the macroeconomy" by Katja Hanewald, January 2009.

009 "Stochastic Population Forecast for Germany and its Consequence for the German Pension System" by Wolfgang Härdle and Alena Mysickova, February 2009.

010 "A Microeconomic Explanation of the EPK Paradox" by Wolfgang Härdle, Volker Krätschmer and Rouslan Moro, February 2009.

011 "Defending Against Speculative Attacks" by Tijmen Daniëls, Henk Jager and Franc Klaassen, February 2009.

012 "On the Existence of the Moments of the Asymptotic Trace Statistic" by Deniz Dilan Karaman Örsal and Bernd Droge, February 2009.

013 "CDO Pricing with Copulae" by Barbara Choros, Wolfgang Härdle and Ostap Okhrin, March 2009.

014 "Properties of Hierarchical Archimedean Copulas" by Ostap Okhrin, Yarema Okhrin and Wolfgang Schmid, March 2009.

015 "Stochastic Mortality, Macroeconomic Risks, and Life Insurer Solvency" by Katja Hanewald, Thomas Post and Helmut Gründl, March 2009.

016 "Men, Women, and the Ballot Woman Suffrage in the United States" by Sebastian Braun and Michael Kvasnicka, March 2009.

017 "The Importance of Two-Sided Heterogeneity for the Cyclicality of Labour Market Dynamics" by Ronald Bachmann and Peggy David, March 2009.

018 "Transparency through Financial Claims with Fingerprints - A Free Market Mechanism for Preventing Mortgage Securitization Induced Financial Crises" by Helmut Gründl and Thomas Post, March 2009.

019 "A Joint Analysis of the KOSPI 200 Option and ODAX Option Markets Dynamics" by Ji Cao, Wolfgang Härdle and Julius Mungo, March 2009.

020 "Putting Up a Good Fight: The Galí-Monacelli Model versus 'The Six Major Puzzles in International Macroeconomics'", by Stefan Ried, April 2009.

021 "Spectral estimation of the fractional order of a Lévy process" by Denis Belomestny, April 2009.

022 "Individual Welfare Gains from Deferred Life-Annuities under Stochastic Lee-Carter Mortality" by Thomas Post, April 2009.

\section{SFB 649, Spandauer Straße 1, D-10178 Berlin http:/ / sfb649.wiwi.hu-berlin.de}




\section{SFB 649 Discussion Paper Series 2009}

For a complete list of Discussion Papers published by the SFB 649, please visit http: //sfb649. wiwi.hu-berlin. de.

023 "Pricing Bermudan options using regression: optimal rates of convergence for lower estimates" by Denis Belomestny, April 2009.

024 "Incorporating the Dynamics of Leverage into Default Prediction" by Gunter Löffler and Alina Maurer, April 2009.

025 "Measuring the effects of geographical distance on stock market correlation" by Stefanie Eckel, Gunter Löffler, Alina Maurer and Volker Schmidt, April 2009.

026 "Regression methods for stochastic control problems and their convergence analysis" by Denis Belomestny, Anastasia Kolodko and J ohn Schoenmakers, May 2009.

027 "Unionisation Structures, Productivity, and Firm Performance" by Sebastian Braun, May 2009.

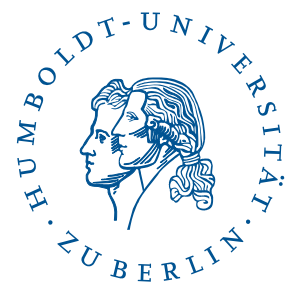

